\title{
藏南喜马拉雅淡色花岗岩稀有金属成矿作用 初步研究
}

\author{
王汝成 ${ }^{1^{*}}$, 吴福元 ${ }^{2}$, 谢否 $^{1}$, 刘小驰 ${ }^{2}$, 王佳敏 ${ }^{2}$, 杨雷 ${ }^{2}$, 赖文 $^{1}$, 刘晨 ${ }^{1}$ \\ 1. 南京大学内生金属矿床成矿机制研究国家重点实验室, 南京大学地球科学与工程学院, 南京 210023; \\ 2. 中国科学院地质与地球物理研究所岩石圈演化国家重点实验室, 北京 100029 \\ *E-mail: rcwang@nju.edu.cn
}

收稿日期: 2017-01-21; 接受日期: 2017-06-22; 网络版发表日期: 2017-07-27

国家自然科学基金项目(批准号: 41230315和41130313)和中央高校基本科研业务费专项资金项目(编号: 020614380057)资助

\begin{abstract}
摘要喜马拉雅淡色花岗岩是青藏高原广泛分布且独具特色的地质组成, 呈东西向分布, 延绵超过 $1000 \mathrm{~km}$. 它们可划分为黑云母花岗岩、二云母/白云母花岗岩、电气石花岗岩和石榴石花岗岩, 此外, 发育程度不等的钠 长石花岗岩和花岗伟晶岩. 本文介绍了对喜马拉雅淡色花岗岩稀有金属成矿的初步研究结果. 在本次调查的 15 个淡色花岗岩体岩体中, 有 12 个岩体中发现了稀有金属矿物, 包括代表铍成矿的绿柱石, 代表铌钽成矿的铌铁矿 族矿物、重钽铁矿、烧绿石一细晶石、褐钎铌矿、铌铁金红石, 代表锡成矿的锡石等。初步研究表明, 喜马拉雅 淡色花岗岩的稀有金属成矿范围广, 具有良好的稀有金属成矿潜力, 可成为中国重要的稀有金属成矿带, 未来需 要尽快加强该地区的稀有金属成矿调查和研究工作, 为中国稀有金属矿产资源接替基地的找寻提供理论依据.
\end{abstract}

关键词淡色花岗岩, 绿柱石, 铌铁矿族矿物, 锡石, 稀有金属成矿, 喜马拉雅, 藏南

\section{1 引言}

稀有金属成矿作用与高演化、强过铝花岗岩(包 括花岗伟晶岩)关系密切(Linnen和Cuney, 2005), 最典 型的稀有金属花岗岩包括欧州海西期花岗岩(如法国 的Beauvoir花岗岩, Cuney等, 1992; 捷克的Cínovec花岗 岩, Rub等, 1998)和华南燕山期花岗岩(如江西宜春花 岗岩, Yin等, 1995; Huang等, 2002). 青藏高原南部喜马 拉雅地区广泛分布的淡色花岗岩是该地区的重要地 质组成(Zhang等, 2012; 吴福元等, 2015), 是国际上最
具特色的花岗岩区之一, 特别是在岩石学方面表现出 与稀有金属花岗岩类似的特征. 因此, 这些稀有金属 成矿作用值得高度关注, 但是前人西藏花岗岩中稀有 金属成矿作用的研究成果较少, 仅在加布拉、告乌、 错那和扎西康铅锌矿区的伟晶岩中报道过绿柱石的 存在(应思淮, 1973; 涂光炽等, 1982; 赖杨等, 2015; Xie 等, 2015, 2017). 我们于2016年夏针对这一问题开展了 野外调查工作, 并对采集的样品进行进一步矿物鉴定 后, 初步确定了喜马拉雅淡色花岗岩稀有金属成矿作 用的类型及分布范围.

中文引用格式: 王汝成, 吴福元, 谢否, 刘小驰, 王佳敏, 杨雷, 赖文, 刘晨. 2017. 藏南喜马拉雅淡色花岗岩稀有金属成矿作用初步研究. 中国科学: 地球 科学, 47: 871-880, doi: 10.1360/N072017-00036

英文引用格式： Wang R C, Wu F Y, Xie L, Liu X C, Wang J M, Yang L, Lai W, Liu C. 2017. A preliminary study of rare-metal mineralization in the Himalayan leucogranite belts, South Tibet. Science China Earth Sciences, doi: 10.1007/s11430-017-9075-8 


\section{2 喜马拉雅淡色花岗岩概述}

喜马拉雅淡色花岗岩带总体上呈东西向分布, 延 绵超过 $1000 \mathrm{~km}$, 并按照其分布特征划分为南部的高喜 马拉雅淡色花岗岩带和北部的特提斯喜马拉雅淡色 花岗岩带. 高喜马拉雅的淡色花岗岩多以规模不等的 岩席形式直接侵入到高喜马拉雅变质岩系之中, 并明 显受到藏南拆离断层(STDS)构造控制, 而特提斯喜马 拉雅淡色花岗岩主要以独立侵入体形式侵入于特提 斯喜马拉雅岩系之中, 或位于特提斯变质穹窂核部. 在后者情况下, 穹窡的主体是变质的高喜马拉雅结晶 岩系, 外侧是特提斯喜马拉雅变质沉积岩系(Harrison 等, 1997; King等, 2011; Zeng等, 2011; Hou等, 2012; 吴 福元等, 2015). 在中国境内, 高喜马拉雅淡色花岗岩有 错那、错那洞、洛扎、库拉岗日、顶噶、告乌、定 结、聂拉木、吉隆和纳木纳尼等岩体, 而特提斯喜马 拉雅淡色花岗岩有打拉、雅拉香波、然巴、康马、苦 堆、麻布加、拉轨岗日、夏如、佩枯错和马拉山等 岩体(图1). 它们规模不等, 小的面积仅数平方公里(如 聂拉木), 但规模大者可达千余平方公里(如库拉岗日).

根据组成矿物的类型和含量, 这些淡色花岗岩 可划分为黑云母花岗岩、二云母/白云母花岗岩、电
气石花岗岩和石榴石花岗岩(吴福元等, 2015; Gou等, 2016; 林涁等, 2016; Liu X C等, 2016; Liu Z C等, 2014, 2016). 其中黑云母花岗岩分布较少, 目前仅发现打拉 岩体符合这一类型.二云母花岗岩分布较为普遍, 在 然巴、拉轨岗日、马拉山、夏如、错那和错那洞等 岩体中均有出露. 电气石花岗岩以告乌岩体大面积出 露为代表, 而石榴石花岗岩的代表是佩枯错岩体. 除 打拉和马拉山岩体外, 所有这些花岗岩体都发育程度 不等的钠长石花岗岩和花岗伟晶岩. 另外, 本次考察 还发现, 同一岩体中不同类型岩石共存的现象很普遍. 如在告乌岩体中, 有(电气石)白云母花岗岩、(电气石) 钠长石花岗岩、(电气石)伟晶岩等, 但目前还难以准 确界定每种岩石类型的出露面积.

钠长石花岗岩常出现在二云母花岗岩、石榴石 花岗岩或电气石花岗岩的边部或顶部, 它们之间的界 限比较清晰(图2a). 钠长石花岗岩有时还会作为伟晶 岩的边部带出现. 钠长石花岗岩多为细粒, 光学显微 镜下观察表明, 造岩矿物多以石英、钠长石为主(图 $2 b)$, 少部分白云母、钾长石, 有时会出现红色锰铝榴 石或黑电气石.

伟晶岩有时以团块状或囊状出现在淡色花岗岩 体的内部, 与寄主岩之间为渐变过渡关系, 反映其为

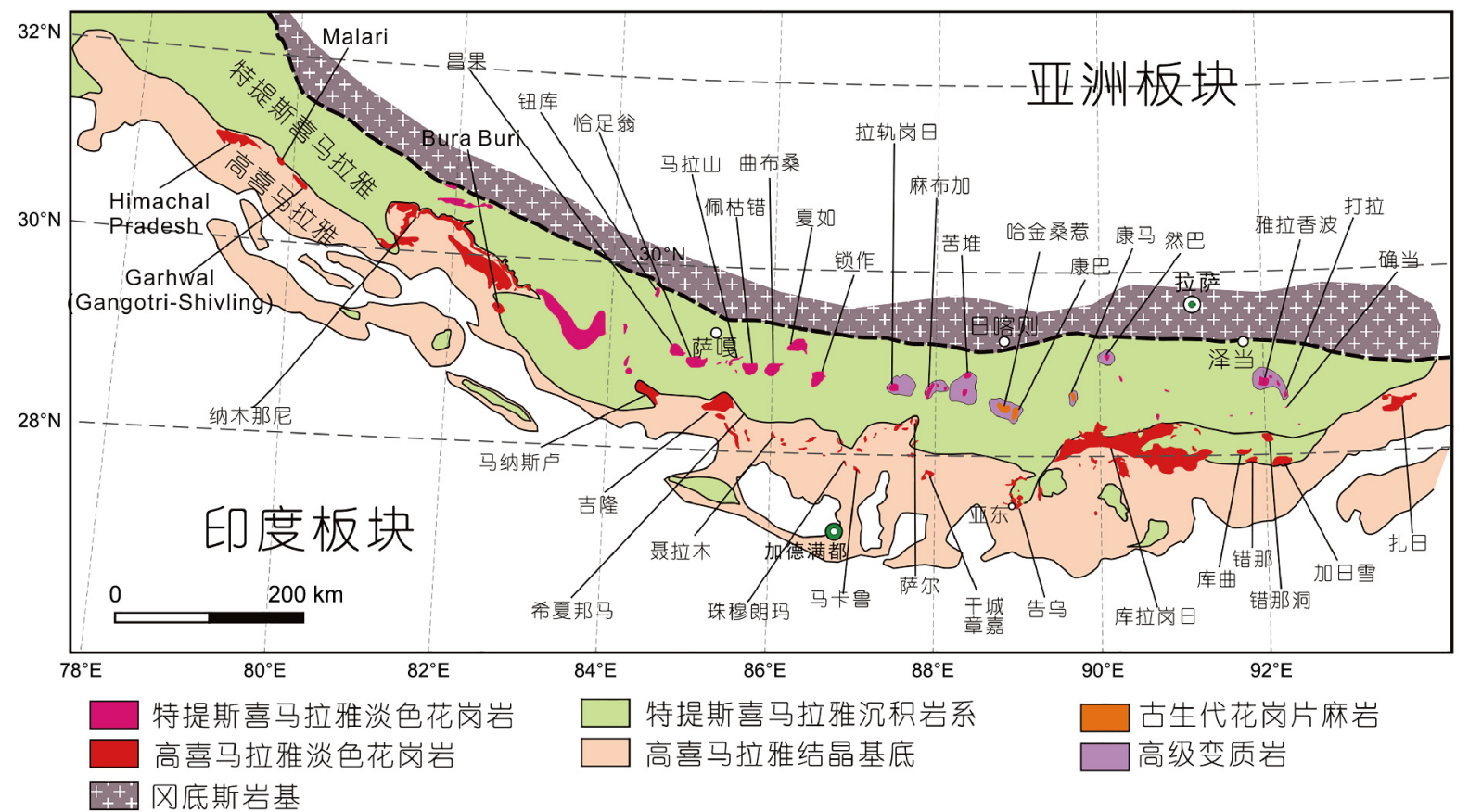

图 1 西藏喜马拉雅淡色花岗岩分布 据吴福元等(2015) 

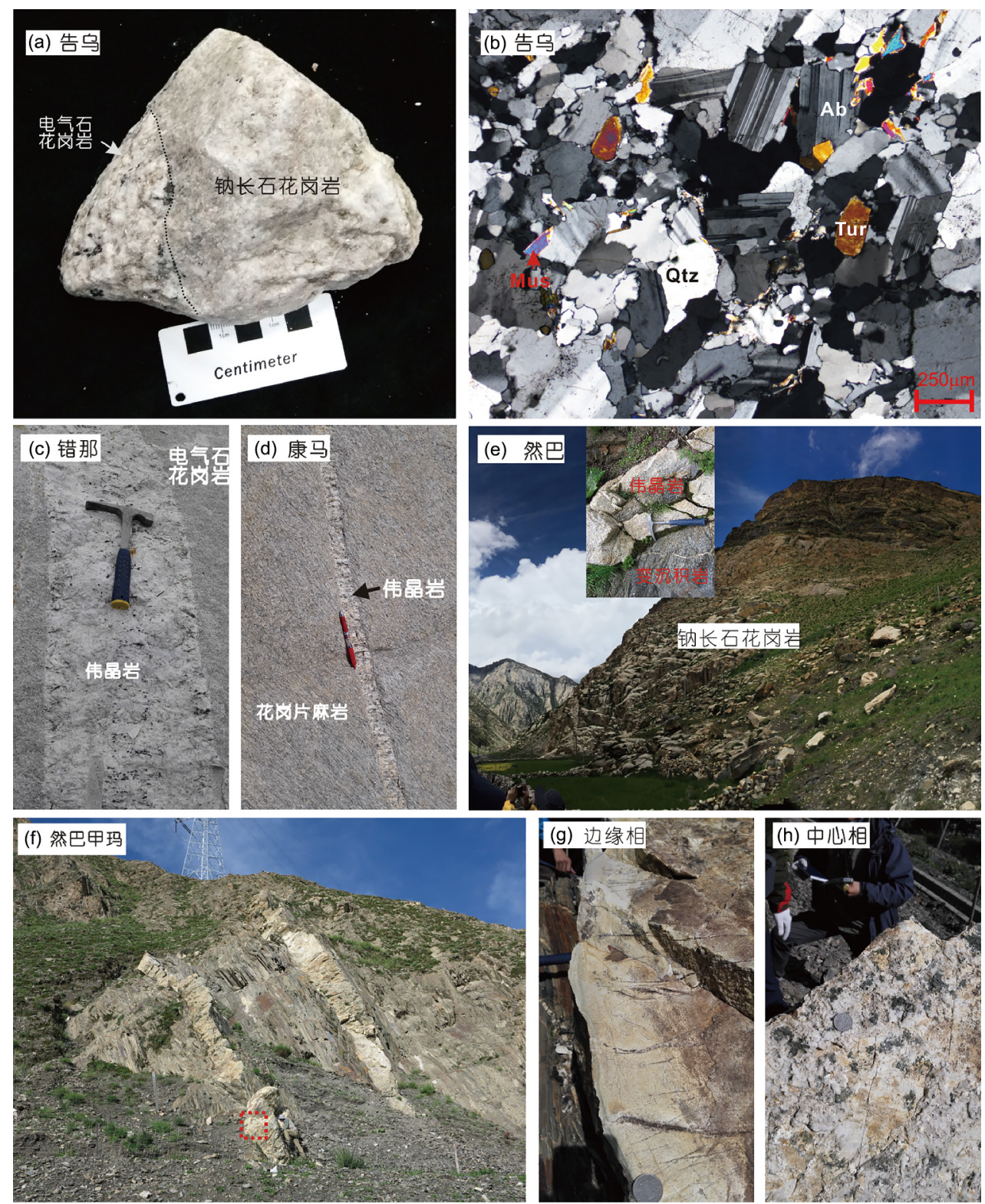

图 2 喜马拉雅地区的淡色花岗岩-伟晶岩

(a) 告乌钠长石花岗岩, 与电气石花岗岩接触界线清晰, 该样品中发现钽铁矿; (b) 告乌钠长石花岗岩的偏光显微镜照片(正交), 由石英( Qtz)、 钠长石 (Ab)、白云母(Mus)、电气石(Tur)等组成; (c) 错那细粒电气石花岗岩中的伟晶岩脉; (d) 康马花岗片麻岩中的伟晶岩脉; (e) 然巴二云 母花岗岩体顶部的伟晶岩脉, 插图显示伟晶岩脉呈似层状侵入到特提斯喜马拉雅变质岩中; (f) 然巴甲玛的花岗伟晶岩脉, 侵入然巴穹窟外 围低级变质岩中, 图中方框内的分带为: 边部相为细晶岩 $(\mathrm{g})$, 中心相为块状钾长石 + 石英 $(\mathrm{h})$

淡色花岗岩原地结晶分异作用的产物. 但大多数情况 下, 伟晶岩呈脉状穿插于淡色花岗岩之中, 抑或在岩 体顶部呈层分布(图2c e ). 这些伟晶岩的主要矿物组 成为石英、钾长石、白云母, 少量钠长石, 有时可出 现石榴石、电气石等. 部分岩体伟晶岩规模较大, 如 雅拉香波岩体, 伟晶岩在其内部普遍发育, 甚至连正
常的淡色花岗岩都难以见及. 在仁布县甲玛村附近的 然巴岩体西侧, 两条花岗伟晶岩脉宽约 $1.5 \mathrm{~m}$ (图2f), 长 超过 $1 \mathrm{~km}$, 并且分带清晰, 边部为细晶岩, 核部为块状 钾长石和石英(图 $2 \mathrm{~g}$ 和 $\mathrm{h}$ ). 从元素成分来看, 喜马拉雅 淡色花岗岩均为过铝, 甚至是强过铝花岗岩(铝饱和指 数ASI $>1.0$, 大部分情况下 $>1.1)$, 与华南稀有金属花岗 
岩(如宜春、栗木、香花岭)或法国Beauvoir花岗岩的 岩石化学特征基本相似(吴福元等, 2015).

\section{3 初步研究结果}

普遍认为, 稀有金属成矿作用与花岗质岩浆结 晶、演化过程有关, 熔体中稀有元素的行为控制稀有 金属成矿的发生, 稀有元素在熔体中过饱和导致稀有 金属矿物结晶, 并进而形成稀有金属成矿。下面将介 绍喜马拉雅淡色花岗岩中发现的稀有金属矿物初步 研究成果.

\section{1 铍}

花岗岩、花岗伟晶岩中的主要铍矿物包括绿柱 石、金绿宝石和磷铍钻石等. 在调查的大部分喜马拉 雅淡色花岗岩体中, 我们在花岗伟晶岩或钠长石花岗 岩的野外露头上均发现了绿柱石, 说明铍矿化在喜马 拉雅淡色花岗岩中具有相当的普遍性. 采集的绿柱石 晶体柱状晶形发育完好, 六方柱面发育较好, 最大的 晶体可达 $1 \mathrm{~cm} \times 1 \mathrm{~cm} \times 3 \mathrm{~cm}$, 淡绿色至深绿色, 有些颗粒 可达海蓝宝石级别. 特别是在然巴、夏如、告乌、错 那和错那洞等伟晶岩中, 绿柱石含量明显较高(图3). 电子探针和LA-ICPMS 的初步分析均显示, 这些绿柱 石可含微量 $\mathrm{Fe} 、 \mathrm{Na} 、 \mathrm{~K} 、 \mathrm{Rb} 、 \mathrm{Cs}$ 和 $\mathrm{Li}$ 等, 计算和测定 的结果相符(表1). 与新疆阿尔泰3号伟晶岩脉和福建
南平31号伟晶岩脉中的原生绿柱石成分相近(Wang等, 2009; Rao等, 2011).

\section{2 铌-钽}

铌、钽是稀有金属成矿的代表性元素. 我们在喜 马拉雅淡色花岗岩中发现的铌、钽矿物种类多达 5 种, 按照出现的几率分别是(从高到低): 铌铁矿-钽铁矿、 烧绿石-细晶石、铌铁金红石、褐钎铌矿和重锄铁矿.

铌铁矿一钽铁矿族矿物是最常见的铌钽矿物, 在告 乌、夏如、错那、错那洞、然巴、顶噶和定结等地 伟晶岩中均有发现, 特别是在前 4 个岩体中铌钽矿物 最为丰富, 具典型板柱状晶形, 内部具环带构造(图4). 除伟晶岩外, 我们在告乌岩体的钠长石花岗岩(图2a) 中还发现钽铁矿. 从电子探针成分分析结果来看, 这 些铌钽矿物类型复杂, 主要有铌铁矿和铌锰矿, 少量为 钽锰矿、钽铁矿、重钽铁矿 (表 $2 ;$ 图4f). 此外, 这些铌 铁矿还可含有一定量的 $\mathrm{W}\left(\right.$ 最高 $3.3 \mathrm{wt} \% \mathrm{WO}_{3}$ ) 和 $\mathrm{Sn}($ 最 高 $6.2 \mathrm{wt} \% \mathrm{SnO}_{2}$ ), 反映可能在区内也有一定规模 $\mathrm{W}-\mathrm{Sn}$ 成矿作用.

烧绿石-细晶石在定结、然巴甲玛、康马、告乌 和错那洞五地发现, 从电子探针分析结果看, 它们含 有 $5 \sim 10 \mathrm{wt} \% \mathrm{UO}_{2}$, 可以将其归于铀烧绿石或铀细晶石 为主, 可交代铌铁矿(图4b).

铌铁金红石是一种富铌(钽)的金红石矿物, 在佩 枯措、然巴甲玛、顶噶、定结、苯堆和错那洞等岩
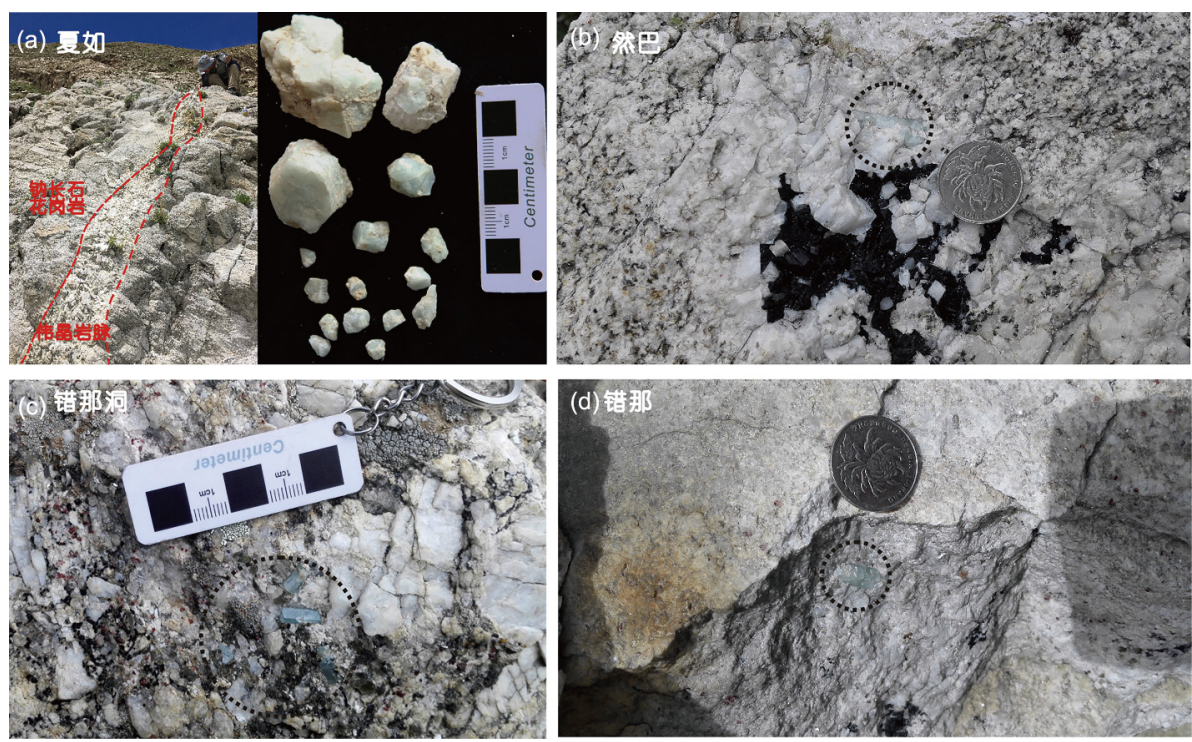

图 3 野外露头上发现的绿柱石晶体

(a)含绿柱石晶体的伟晶岩脉(夏如); (b) (d)分别为然巴、错那洞和错那团块状伟晶岩中的绿柱石(圆圈内的淡绿色柱状晶体) 
表 1 喜马拉雅淡色花岗岩中部分绿柱石化学成分 $(w t \%)^{\mathrm{a})}$

\begin{tabular}{|c|c|c|c|c|c|c|c|c|c|c|c|c|}
\hline & & $\mathrm{SiO}_{2}$ & $\mathrm{Al}_{2} \mathrm{O}_{3}$ & $\mathrm{FeO}$ & $\mathrm{CaO}$ & $\mathrm{BeO}$ & $\mathrm{Li}_{2} \mathrm{O}$ & $\mathrm{Na}_{2} \mathrm{O}$ & $\mathrm{K}_{2} \mathrm{O}$ & $\mathrm{Rb}_{2} \mathrm{O}$ & $\mathrm{Cs}_{2} \mathrm{O}$ & 总量 \\
\hline \multicolumn{13}{|l|}{$\underline{\text { EMPA }}$} \\
\hline \multirow[t]{2}{*}{ 然巴 } & 1 & 66.94 & 17.50 & 0.03 & 0.00 & 13.38 & 0.33 & 0.21 & 0.00 & 0.03 & 0.06 & 98.49 \\
\hline & 2 & 64.46 & 18.48 & 0.30 & 0.02 & 12.89 & 0.32 & 0.30 & 0.01 & 0.10 & 0.05 & 96.91 \\
\hline \multirow[t]{2}{*}{ 错那 } & 3 & 65.40 & 17.83 & 0.31 & - & 13.61 & 0.18 & 0.34 & 0.02 & 0.02 & 0.12 & 97.64 \\
\hline & 4 & 65.88 & 17.66 & 0.48 & 0.02 & 13.71 & 0.30 & 0.58 & 0.02 & 0.04 & 0.07 & 98.46 \\
\hline \multirow[t]{2}{*}{ 错那洞 } & 5 & 65.35 & 17.69 & 0.37 & 0.01 & 13.60 & 0.26 & 0.51 & 0.03 & 0.04 & - & 97.60 \\
\hline & 6 & 65.83 & 17.69 & 0.58 & - & 13.70 & 0.31 & 0.64 & 0.01 & 0.03 & - & 98.47 \\
\hline \multirow[t]{2}{*}{ 夏如 } & 7 & 65.48 & 17.55 & 0.76 & 0.03 & 13.63 & 0.30 & 0.59 & 0.02 & 0.02 & 0.07 & 98.14 \\
\hline & 8 & 65.63 & 17.73 & 0.74 & - & 13.66 & 0.27 & 0.55 & 0.01 & 0.06 & 0.06 & 98.42 \\
\hline \multicolumn{13}{|c|}{$\underline{\text { LA-ICPMS }}$} \\
\hline 错那洞 & $(n=48)$ & 63.91 & 17.85 & 0.71 & - & 12.72 & 0.41 & 0.74 & 0.03 & 0.01 & 0.19 & \\
\hline 夏如 & $(n=8)$ & 63.91 & 18.30 & 0.89 & - & 12.80 & 0.31 & 0.80 & 0.02 & 0.01 & 0.16 & \\
\hline
\end{tabular}

a) Be和 $\mathrm{Li}$ 含量是根据完全化学配比计算获得, $\mathrm{Li}=1-\mathrm{K}+\mathrm{Na}+\mathrm{Rb}+\mathrm{Cs} ; \mathrm{Be}=3-\mathrm{Li}$. -: 低于检测限

体中少量存在. 它们的 $(\mathrm{Nb}, \mathrm{Ta})_{2} \mathrm{O}_{5}$ 含量较高(可超过 $20 \mathrm{wt} \%$ ), 所分析的金红石大部分富集 $\mathrm{Nb}$, 然巴甲玛伟 晶岩脉中的金红石 $\mathrm{Nb}_{2} \mathrm{O}_{5}$ 近 $20 \mathrm{wt} \%$ (表3), 而康马伟晶 岩中则出现钽铁金红石 $\left(\mathrm{Ta}_{2} \mathrm{O}_{5}\right.$ 约 $\left.17 \mathrm{wt} \%\right)$.

褐钎铌矿是相对比较少见的铌钽矿物, 但在然 巴、康马、佩古错和错那等岩体中都有发现. 特别是 康马和佩枯错两岩体中, 褐钎铌矿是非常重要的铌钽 矿物 (图4e). 错那岩体中褐钎铌矿含量也较高, 且柱 状晶形完好. 褐钎铌矿的成分中, $\mathrm{Y}_{2} \mathrm{O}_{3}$ 含量最高接近 $30 \mathrm{wt} \%$, 其他重稀土元素总量也可达 $10 \mathrm{wt} \%$. 此外, 它 还含有 $5 \sim 10 \mathrm{wt} \%$ 的 $\mathrm{UO}_{2}$. 因此, 该矿物呈现出程度不等 的结构蜕晶化现象.

重钽铁矿是演化程度较高的花岗岩或花岗伟晶 岩中才可能出现的钽端元矿物, 但在错那和康马的伟 晶岩中均有发现该矿物(表2). 需要指出的是, 在康马 发现重钽铁矿的样品中, 锆石的 $\mathrm{HfO}_{2}$ 含量高达 $20 \mathrm{wt} \%$, 表明康马花岗伟晶岩的分异程度较高.

\section{3 锡}

相对于铌钽成矿作用, 喜马拉雅淡色花岗岩的 锡成矿规模较小, 也比较局限, 目前仅在错那、错那 洞、然巴钠长石花岗岩或花岗伟晶岩中发现了较多 的锡石, 在雅拉香波和告乌岩体中有少量发现. 这些 锡石共同的特点是 $\mathrm{Nb} 、 \mathrm{Ta}$ 含量较高(表3), 特别是图 $4 \mathrm{~d}$ 中与重钽铁矿共生的锡石, $\mathrm{Ta}_{2} \mathrm{O}_{5}$ 含量达 $15.6 \mathrm{wt} \%$. 在
$(\mathrm{Nb}+\mathrm{Ta})-(\mathrm{Fe}+\mathrm{Mn})$ 图解中, 锡石的成分落在 2:1直线分布 (图5), 显示其为岩浆成因特征(Tindle和Breaks, 1998).

\section{4 锂、钟、铯}

稀碱金属锂、铭、铯经常伴随铍、铌、钽等在高 演化花岗岩中富集. 但是, 目前在喜马拉雅淡色花岗 岩中, 尚未获得它们显著富集的信息, 锂云母、锂辉石 或锂电气石等锂矿物尚未被发现. 在夏如岩体中, 我们 发现一些石英脉中存在细粒片状云母. 据LA-ICPMS 分析, 这些云母最高可含近 $2000 \mathrm{ppm}$ Li. 此外, 几乎所 有的绿柱石也含微量 Li.

但是,有国外学者报道(Visona和Zantedeschi, 1994), 位于卓奥友峰西北普士拉一带的花岗伟晶岩中出现 锂辉石、透锂长石和锡石的矿物组合, 显示锂的矿化 在喜马拉雅地区可能有一定的规模, 只是目前的调查 程度有限.

\section{4 初步结论与未来展望}

\section{1 喜马拉雅地区稀有金属成矿作用}

在本次野外考察的 15 个淡色花岗岩或花岗伟晶岩 中, 有 12 个岩体中发现了稀有金属矿物(表4), 包括代 表铍成矿的绿柱石, 代表铌钽成矿的铌铁矿族矿物、 重钽铁矿、烧绿石-细晶石、褐钎铌矿、铌铁金红石, 代表锡成矿的锡石等. 可见, 喜马拉雅淡色花岗岩的 

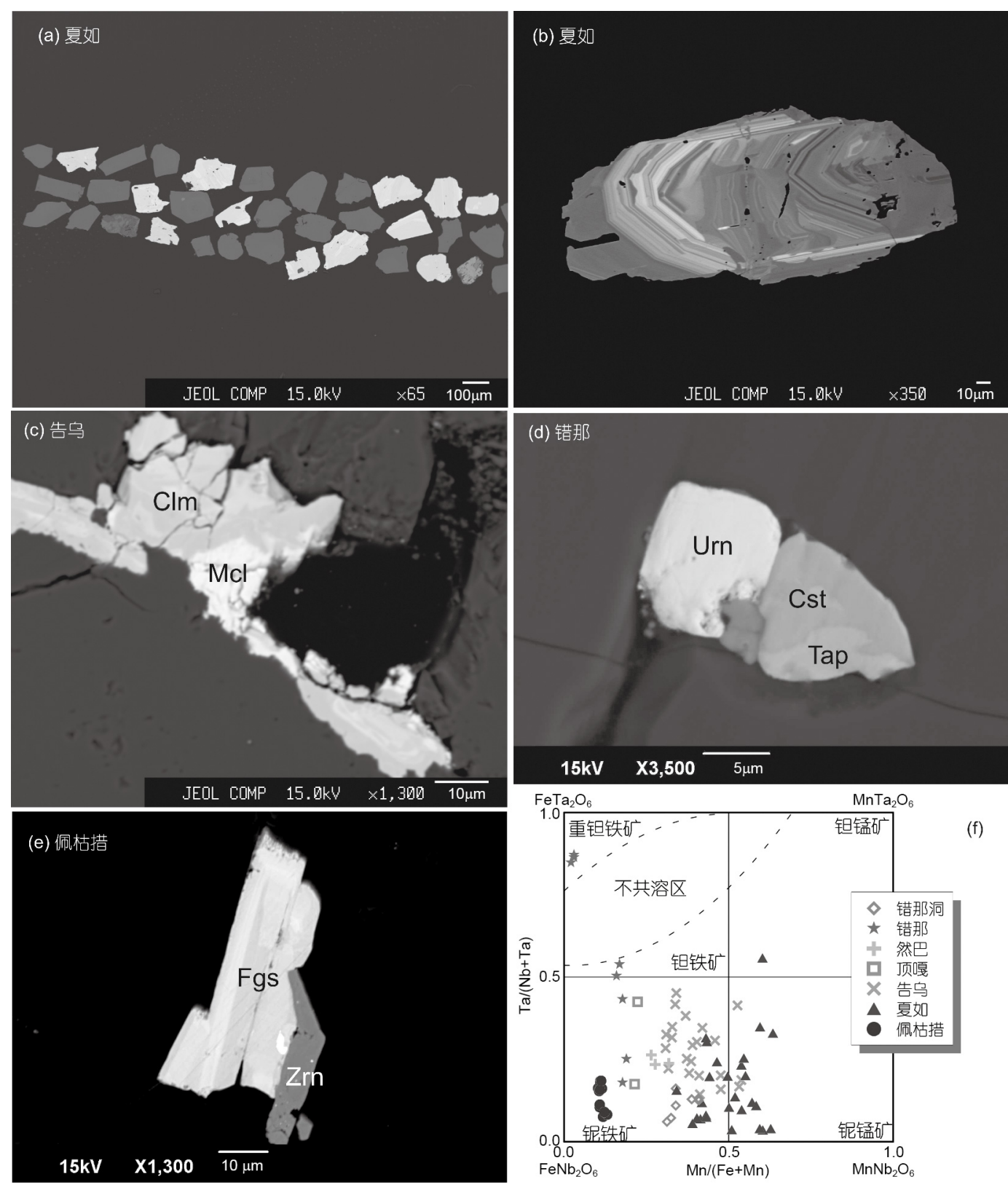

图 4 喜马拉雅淡色花岗岩中的铌钽矿物

(a) 夏如伟晶岩脉中选出的铌铁矿, 如图中较亮的矿物, 暗色为电气石; (b) 夏如具韵律环带构造的铌铁矿; (c) 告乌伟晶岩中铌铁矿 (Clm) 和细晶石 (Mcl); (d) 错那伟晶岩中重钽铁矿(Tap)及共生的富钽锡石(Cst)和晶质铀矿 (Urn); (e) 佩枯措伟晶岩中褐钎铌矿 (Fgs) 及共生的锆石 (Zrn); (f) 铌铁矿族矿物和重钽铁矿的成分投影图

稀有金属成矿范围广, 具有普遍性. 实际上, 与中国 藏南接壤的尼泊尔、不丹及印度的很多地区, 绿柱石 广泛存在于淡色花岗岩及相关的伟晶岩中(Le Fort等, 1987; Scaillet等, 1990; Searle等, 1993). 在尼泊尔, 还有 海蓝宝石级别的绿柱石在开采和贸易, 足以显示喜马 拉雅地区铍成矿作用的巨大潜力.
还需要指出的是, 在稀有金属花岗岩的分布上, 特 提斯喜马拉雅带中几个大型穹窡中淡色花岗岩的稀有 金属富集尤其明显, 如夏如、佩枯错、康马和然巴等. 在高喜马拉雅带中, 聂拉木一带的淡色花岗岩目前还 没发现有稀有金属矿化痕迹, 但其以东的普士拉、定 结、告乌、错那和错那洞等岩体却发育有各种类型 
表 2 喜马拉雅淡色花岗岩中部分铌钽矿物的电子探针成分 $(w t \%)$

\begin{tabular}{|c|c|c|c|c|c|c|c|c|c|c|c|}
\hline & $\begin{array}{c}\text { 告乌 } \\
\text { 铌铁矿 }\end{array}$ & $\begin{array}{c}\text { 告乌 } \\
\text { 铌铁矿 }\end{array}$ & $\begin{array}{l}\text { 错那洞 } \\
\text { 铌铁矿 }\end{array}$ & $\begin{array}{c}\text { 错那 } \\
\text { 钽铁矿 }\end{array}$ & $\begin{array}{c}\text { 错那 } \\
\text { 钽铁矿 }\end{array}$ & $\begin{array}{c}\text { 错那 } \\
\text { 重钽铁矿 }\end{array}$ & $\begin{array}{c}\text { 错那 } \\
\text { 重钽铁矿 }\end{array}$ & $\begin{array}{c}\text { 夏如 } \\
\text { 铌锰矿 }\end{array}$ & $\begin{array}{c}\text { 夏如 } \\
\text { 铌铁矿 }\end{array}$ & $\begin{array}{c}\text { 康马 } \\
\text { 钽铁矿 }\end{array}$ & $\begin{array}{c}\text { 康马 } \\
\text { 重钽铁矿 }\end{array}$ \\
\hline $\mathrm{WO}_{3}$ & 0.26 & 0.38 & - & 0.71 & 1.06 & 0.05 & 0.17 & 1.17 & 1.83 & 0.39 & 0.50 \\
\hline $\mathrm{Nb}_{2} \mathrm{O}_{5}$ & 35.64 & 54.79 & 68.00 & 27.35 & 29.24 & 6.29 & 7.43 & 61.76 & 54.45 & 17.87 & 17.05 \\
\hline $\mathrm{Ta}_{2} \mathrm{O}_{5}$ & 42.47 & 23.90 & 8.87 & 53.11 & 49.41 & 71.29 & 69.01 & 13.99 & 22.41 & 53.42 & 53.11 \\
\hline $\mathrm{TiO}_{2}$ & 2.47 & 1.08 & 1.03 & 1.07 & 1.66 & 3.45 & 3.65 & 1.93 & 1.64 & 8.84 & 8.96 \\
\hline $\mathrm{SnO}_{2}$ & 0.63 & 0.26 & 0.17 & 0.08 & 0.21 & 6.18 & 2.99 & 0.02 & 0.11 & 0.12 & 0.14 \\
\hline $\mathrm{MnO}$ & 5.99 & 7.41 & 6.62 & 2.49 & 2.46 & 0.38 & 0.27 & 11.62 & 8.53 & 0.46 & 0.45 \\
\hline $\mathrm{FeO}$ & 11.88 & 12.22 & 13.92 & 12.42 & 13.18 & 12.46 & 12.78 & 8.82 & 10.92 & 19.44 & 19.50 \\
\hline 总量 & 99.33 & 100.06 & 98.61 & 97.24 & 97.21 & 100.10 & 96.29 & 99.32 & 99.90 & 100.55 & 99.70 \\
\hline
\end{tabular}

表 3 喜马拉雅淡色花岗岩中部分金红石和锡石的成分 (wt\%)

\begin{tabular}{|c|c|c|c|c|c|c|}
\hline & \multicolumn{3}{|c|}{ 金红石 } & \multicolumn{3}{|c|}{ 锡石 } \\
\hline & 然巴甲玛 & 康马 & 康马 & 告乌 & 错那洞 & 错那 \\
\hline $\mathrm{WO}_{3}$ & - & 0.02 & - & - & - & - \\
\hline $\mathrm{Nb}_{2} \mathrm{O}_{5}$ & 19.32 & 9.34 & 9.28 & 0.59 & 2.22 & 0.99 \\
\hline $\mathrm{Ta}_{2} \mathrm{O}_{5}$ & 4.71 & 16.70 & 17.58 & 3.70 & 0.27 & 15.65 \\
\hline $\mathrm{TiO}_{2}$ & 66.93 & 62.37 & 62.06 & 0.96 & 0.77 & 0.623 \\
\hline $\mathrm{SnO}_{2}$ & 0.05 & 0.22 & 0.29 & 93.57 & 95.33 & 79.26 \\
\hline $\mathrm{MnO}$ & 0.02 & - & 0.07 & 0.06 & 0.17 & 0.12 \\
\hline $\mathrm{FeO}$ & 7.53 & 9.37 & 9.75 & 0.72 & 0.81 & 2.80 \\
\hline 总量 & 98.57 & 98.03 & 99.04 & 99.59 & 99.56 & 99.44 \\
\hline
\end{tabular}

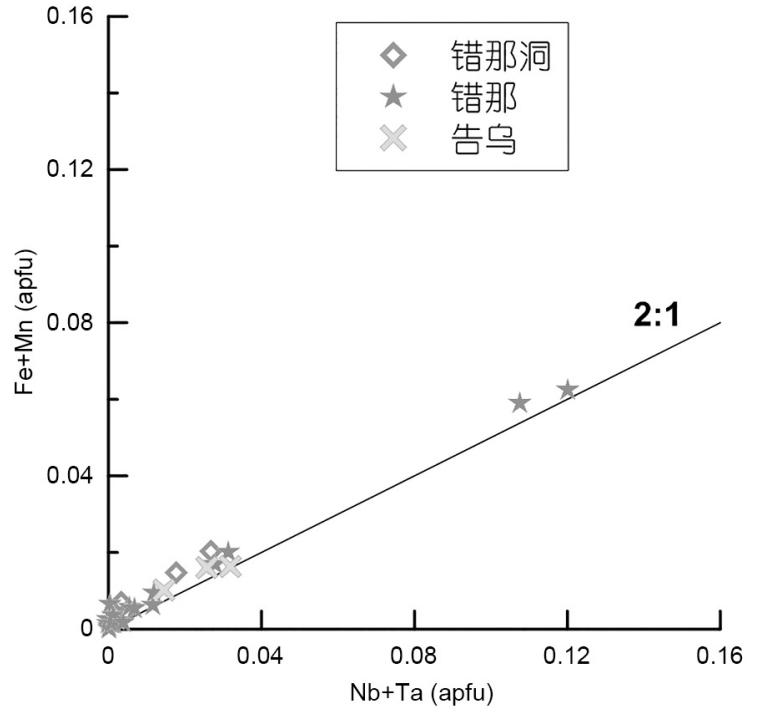

图 5 喜马拉雅淡色花岗岩中锡石的 $\mathrm{Nb}+\mathrm{Ta}-\mathrm{Fe}+\mathrm{Mn}$ 投影图

的稀有金属成矿作用. 因此两条淡色花岗岩带均显示 有一定成矿作用, 目前的资料还难以说明高喜马拉雅
和特提斯喜马拉雅稀有金属成矿作用是否存在差别. 但对比稀有金属成矿组合可以发现, 藏南喜马拉雅淡 色花岗岩带的东段, 如告乌、然巴、错那和错那洞等, 成矿组合主要为Nb-Ta-Sn-Be, 而在花岗岩带相对偏西 的花岗岩, 如夏如、定结、佩枯措等, 成矿组合主要 是Nb-Ta-Be, 目前尚未发现锡成矿. 因此, 初步的研究 结果显示, 喜马拉雅淡色花岗岩带的稀有金属成矿可 能具有一定的区域性, 但与岩体的构造特征及其岩体 的大小并无特别的关联.

另一个值得关注的问题是这些稀有金属成矿作用 发生的年代. 吴福元等(2015)曾将喜马拉雅淡色花岗岩 划分为原喜马拉雅(46 26Ma)、新喜马拉雅(26 13Ma) 和后喜马拉雅(13 7Ma)三个阶段. 其中第一阶段主要 发生在特提斯喜马拉雅, 而后两者发育的程度和规模 在特提斯喜马拉雅和高喜马拉雅之间并无显著差别. 目前的调查显示, 上述三阶段淡色花岗岩体均伴有稀 有金属矿化. 但须指出, 原喜马拉雅阶段形成的打拉和 确当岩体, 以及与其相关的恰嘎流纹斑岩等 $(42 \mathrm{Ma})$, 
表 4 喜马拉雅淡色花岗岩中稀有金属矿物的分布

\begin{tabular}{|c|c|c|c|c|c|c|c|c|c|c|c|c|}
\hline & 佩枯措 & 夏如 & 定结 & 告乌 & 顶噶 & 然巴甲玛 & 然巴 & 康马 & 苯堆 & 雅拉香波 & 错那洞 & 错那 \\
\hline $\begin{array}{l}\text { 银铁矿- } \\
\text { 钽铁矿 }\end{array}$ & - & - & - & - & - & & - & & & & • & - \\
\hline $\begin{array}{l}\text { 烧绿石- } \\
\text { 细晶石 }\end{array}$ & & • & & - & & - & - & • & & & • & \\
\hline 重锄铁矿 & & & & & & & & - & & & & • \\
\hline $\begin{array}{l}\text { 铌铁金 } \\
\text { 红石 }\end{array}$ & - & & - & & - & • & & • & . & & • & \\
\hline 褐钎铌矿 & - & & & & & & • & - & & & - & - \\
\hline 锡石 & & & & - & & & • & & & - & • & - \\
\hline 绿柱石 & - & 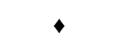 & - & 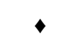 & & & - & • & & & - & - \\
\hline $\begin{array}{c}\text { 成矿元素 } \\
\text { 组合 }\end{array}$ & $\mathrm{NbTa}-\mathrm{Be}$ & $\mathrm{NbTa}-\mathrm{Be}$ & $\mathrm{NbTa}-\mathrm{Be}$ & $\begin{array}{l}\mathrm{NbTa}- \\
\mathrm{Be}-\mathrm{Sn}\end{array}$ & $\mathrm{NbTa}$ & $\mathrm{NbTa}-\mathrm{Be}$ & $\begin{array}{l}\mathrm{NbTa}- \\
\mathrm{Be}-\mathrm{Sn}\end{array}$ & $\begin{array}{l}\mathrm{NbT} \\
-\mathrm{Be}\end{array}$ & $\mathrm{NbTa}$ & $\mathrm{Sn}$ & $\begin{array}{l}\text { NbTa- } \\
\text { Be-Sn }\end{array}$ & $\begin{array}{l}\text { NbTa- } \\
\text { Be-Sn }\end{array}$ \\
\hline
\end{tabular}

基本不发育伟晶岩和钠长花岗岩, 因而未见稀有金属 矿化. 在雅拉香波穹窒内部, 早阶段( 40Ma)形成的伟 晶岩基本不显示稀有金属矿化, 但中新世形成的淡色 花岗岩-伟晶岩显示Sn矿化(表4), 两者差别的原因有 待进一步研究.

中国是稀有金属资源大国,特别是南岭和新疆阿 尔泰地区是中国两个重要的稀有金属成矿带(陈毓川 等, 1989; 王贤觉等, 1981). 对喜马拉雅淡色花岗岩的 初步研究已经显示了该地区具有良好的稀有金属成 矿潜力, 很可能成为继华南、新疆阿尔泰之后中国又 一个重要的稀有金属成矿带, 未来需要尽快加强该地 区的稀有金属成矿调查和研究工作, 为中国稀有金属 矿产资源接替基地的找寻提供理论依据.

\section{2 喜马拉雅淡色花岗岩成因与演化}

喜马拉雅淡色花岗岩中大量稀有金属矿物的发 现, 为该类型岩石的成因研究提供了重要制约. 目前 普遍认为, 稀有金属成矿作用是花岗质岩浆高度结晶 分异演化的产物. 尽管传统观点认为, 喜马拉雅淡色 花岗岩主要来自高喜马拉雅结晶岩系的原地部分熔融 (Le Fort等, 1987), 并且熔融方式有脱水熔融和注水熔 融两种类型, 从而导致岩浆水含量及岩石特征、矿物 组成及其地球化学特征的差异 (Gao等, 2017). 但最近 的研究发现, 岩浆高度结晶分异作用可能是这些岩石 成分变化更重要的原因(Liu Z C等, 2014, 2016; 吴福元 等, 2015). 支持这一解释的证据不仅包括上述发现的
稀有金属矿物, 还包括岩石的宏观地质特征、岩石的 矿物组成及成分(如Hf含量高的锆石)及岩石的地球化 学成分(如稀土元素的四分组效应)等. 此外, 钠长花岗 岩在以前的喜马拉雅淡色花岗岩研究中从未引起足 够的重视. 但本次野外考察发现, 该类型岩石几乎在 所有岩体中都有所发育. 它或呈脉状单独出现, 或与 伟晶岩伴生. 钠长花岗岩一般被认为是花岗岩浆演化 最晚期的产物, 是花岗岩浆高演化的标志性岩石. 不 同的稀有金属矿物成矿作用的实验岩石学研究表明, 熔体中挥发组份是非常重要的, 如 $\mathrm{H}_{2} \mathrm{O} 、 \mathrm{~L} 、 \mathrm{~F} 、 \mathrm{~B}$ 和 $\mathrm{P}$ 等, 稀有金属花岗岩的流体饱和时, 其中水甚至可以 达到 $8 \mathrm{wt} \%$ (Holtz等, 1993), 在类似的含铇的花岗质熔 体中也达到高于 $2 \mathrm{wt} \%$ 的含水量(Linnen, 2005; Che等, 2013). 同时水的溶解度很大程度上还受到压力和 $\mathrm{CO}_{2}$ 含量的影响(Baker和Alletti, 2012). 这些高含量的挥发 份, 降低了结晶温度, 延长了结晶的时间, 同时也促进 了岩浆的高度分异演化. 因此, 未来应加强淡色花岗 岩成岩过程的研究, 并理解这一过程对稀有金属成矿 作用和喜马拉雅造山作用的认识.

诚然, 本次研究的稀有金属矿物主要来自伟晶岩 和钠长花岗岩, 那是否相伴生的花岗岩也具有稀有金 属成矿潜力值得进一步研究. 根据我们的调查和早期 研究, 大量的花岗岩与伟晶岩之间呈现渐变过渡关系. 即使是呈脉状产出的伟晶岩, 其与花岗岩之间并不存 在我们通常所见的冷凝边或烘烤边, 表明伟晶岩的岩 浆在花岗岩体中运移的距离并不大. 对然巴和夏如岩 


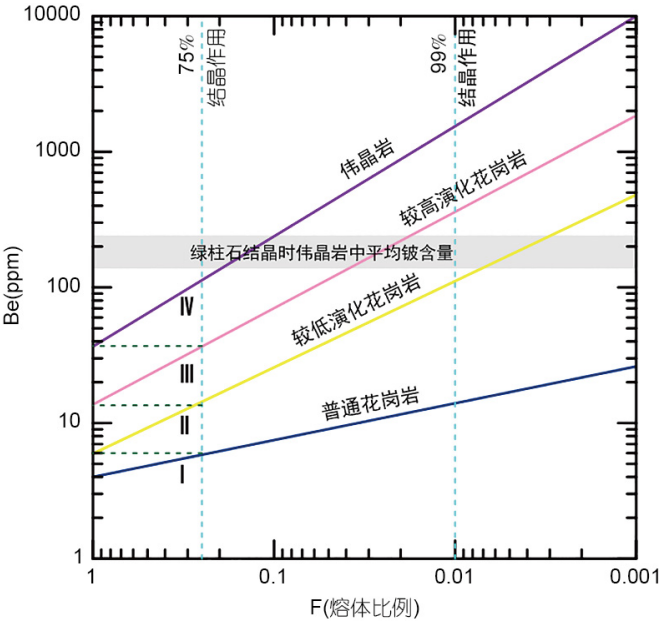

图 6 花岗岩浆分异演化与铍成矿作用 分配系数资料来自London(2015)

体的研究已经发现(Liu Z C等, 2014, 2016), 伟晶岩与 寄主花岗岩在形成时代上完全一致, 暗示它们之间密 切的成因联系.

另一方面, 通常的花岗岩不具有稀有金属成矿特 征. 以铍成矿为例, 通常的花岗岩 $\mathrm{Be}$ 含量约在 $4 \mathrm{ppm}$ 左 右(London和Evensen, 2002), 而绿柱石的结晶要求岩 浆的Be含量大约在 $205 \mathrm{ppm}$ 左右(London, 2015). 通常 的花岗岩浆仅通过单次结晶分异演化将无法达到Be 含量饱和的(图6). 即使演化晚期的最后一滴熔体可能 具有较高的 $\mathrm{Be}$ 含量, 但此时的熔体占整个体系的比例 太低, 它无法从体系中分凝出来形成伟晶岩, 这也是 并非所有伟晶岩都能晶出绿柱石的重要原因. 假如以 $25 \%$ 的比例作为熔体可抽取的临界值, 一个花岗岩浆 体系至少要经过4次结晶分离作用才有可能造成绿柱 石的结晶(图6). 因此, 铍成矿作用的出现必须要求高 分异花岗岩的存在. 同理, Nb-Ta矿化以及 Li-Rb-Cs的 矿化对岩浆分异程度的要求更高, 这就是稀有金属矿 化与高分异花岗岩成因联系密切的关键所在.

\section{致谢衰心感谢两位审稿专家的建议。}

\section{参考文献}

陈毓川, 裴荣富, 张宏良, 林新多, 白鸽, 李崇佑, 胡永嘉, 刘后群, 冼柏 琪. 1989. 南岭地区与中生代花岗岩类有关的有色及稀有金属矿 床地质. 地质专报, 矿床与矿产, 第 10 号. 北京: 地质出版社. 508
赖杨, 周清, 秦建华, 夏祥标, 吴建阳, 李应栩. 2015. 藏南扎西康整装 勘查区岩浆岩地质特征及研究意义. 高校地质学报, 21: 31-42

林彬, 唐菊兴, 郑文宝, 冷秋峰, 林金金, 王艺云, 孟展, 唐攀, 丁帅, 徐云 峰, 袁梅. 2016. 西藏错那洞淡色花岗岩地球化学特征、成岩时 代及岩石成因. 岩石矿物学杂志, 35: 391-406

涂光炽, 张玉泉, 王中刚. 1982. 西藏南部花岗岩类地球化学. 北京: 科学出版社. 190

王贤觉, 邹天人, 徐建国, 于学元, 装愉卓. 1981. 阿尔泰伟晶岩矿物 研究. 北京: 科学出版社. 140

吴福元, 刘志超, 刘小驰, 纪伟强. 2015. 喜马拉雅淡色花岗岩. 岩石 学报, 31: 1-36

应思淮. 1973. 中国西藏南部珠穆朗玛峰地区的岩浆岩、变质岩和 混合岩. 地质科学, 2: 103-132

Baker D R, Alletti M. 2012. Fluid saturation and volatile partitioning between melts and hydrous fluids in crustal magmatic systems: The contribution of experimental measurements and solubility models. Earth-Sci Rev, 114: 298-324

Che X D, Linnen R L, Wang R C, Aseri A, Thibault Y. 2013. Tungsten solubility in evolved granitic melts: An evaluation of magmatic wolframite. Geochim Cosmochim Acta, 106: 84-98

Cuney M, Marignac C, Weisbrod A. 1992. The Beauvoir topaz-lepidolite albite granite (Massif Central, France)-The disseminated magmatic Sn-Li-Ta-Nb-Be mineralization. Econ Geol, 87: 1766-1794

Gao L E, Zeng L S, Asimow P D. 2017. Contrasting geochemical signatures of fluid-absent versus fluid-fluxed melting of muscovite in metasedimentary sources: The Himalayan leucogranites. Geology, 45: $39-42$

Gou Z B, Zhang Z M, Dong X, Xiang H, Ding H X, Tian Z L, Lei H C. 2016. Petrogenesis and tectonic implications of the Yadong leucogranites, southern Himalaya. Lithos, 256-257: 300-310

Harrison T M, Lovera O M, Grove M. 1997. New insights into the origin of two contrasting Himalayan granite belts. Geology, 25: 899-902

Holtz F, Dingwell D B, Behrens H. 1993. Effects of F, $\mathrm{B}_{2} \mathrm{O}_{3}$ and $\mathrm{P}_{2} \mathrm{O}_{5}$ on the solubility of water in haplogranite melts compared to natural silicate melts. Contrib Mineral Petrol, 113: 492-501

Huang X L, Wang R C, Chen X M, Hu H, Liu C S. 2002. Vertical variations in the mineralogy of the Yichun topaz lepidolite granite, Jiangxi Province, Southern China. Can Mineral, 40: 1047-1068

Hou Z Q, Zheng Y C, Zeng L S, Gao L E, Huang K X, Li W, Li Q Y, Fu Q, Liang W, Sun Q Z. 2012. Eocene-Oligocene granitoids in southern Tibet: Constraints on crustal anatexis and tectonic evolution of the Himalayan orogen. Earth Planet Sci Lett, 349-350: 38-52

Le Fort P, Cuney M, Deniel C, France-Lanord C, Sheppard S M F, Upreti B N, Vidal P. 1987. Crustal generation of the Himalayan leucogranites. Tectonophysics, 134: 39-57 
Linnen R L. 2005. The effect of water on accessory phase solubility in subaluminous and peralkaline granitic melts. Lithos, 80: 267-280

Linnen R L, Cuney M. 2005. Granite-related rare-element deposits and experimental constraints on Ta-Nb-W-Sn-Zr-Hf mineralization. In: Linnen R L, Samson I M, eds. Rare-Element Geochemistry and Mineral Deposits. Geol Ass Can GAC Short Course Notes, 17: 45-67

Liu X C, Wu F Y, Yu L J, Liu Z C, Ji W Q, Wang J G. 2016. Emplacement age of leucogranite in the Kampa Dome, southern Tibet. Tectonophysics, 667: 163-175

Liu Z C, Wu F Y, Ji W Q, Wang J G, Liu C Z. 2014. Petrogenesis of the Ramba leucogranite in the Tethyan Himalaya and constraints on the channel flow model. Lithos, 208-209: 118-136

Liu Z C, Wu F Y, Ding L, Liu X C, Wang J G, Ji W Q. 2016. Highly fractionated Late Eocene ( $35 \mathrm{Ma}$ ) leucogranite in the Xiaru Dome, Tethyan Himalaya, South Tibet. Lithos, 240-243: 337-354

London D, Evensen J E. 2002. Beryllium in silicic magmas and the origin of beryl-bearing pegmatites. In: Grew E S, ed. Beryllium: Mineralogy, Petrology, and Geochemistry. Mineral Soc Amer Rev Mineral Geochem, 50: 445-486

London D. 2015. Reading pegmatites: Part 1-What Beryl says. Rocks \& Minerals, 90: 138-153

King J, Harris N, Argles T, Parrish R, Zhang H. 2011. Contribution of crustal anatexis to the tectonic evolution of Indian crust beneath southern Tibet. Geol Soc Am Bull, 123: 218-239

Rao C, Wang R C, Hu H. 2011. Paragenetic assemblages of beryllium silicates and phosphates from the Nanping No.31 granitic pegmatite dyke, Fujian Province, Southeastern China. Can Mineralm, 49: 1175-1187

Rub A K, Stemprok M, Rub M G. 1998. Tantalum mineralization in the apical part of the Cínovec (Zinnwald) granite stock. Mineral Petrol, 63: $199-222$

Scaillet B, France-Lanord C, Le Fort P. 1990. Badrinath-Gangotri plutons (Garhwal, India): Petrological and geochemical evidence for fractionation processes in a high Himalayan leucogranite. J Volcanol Geotherm Res, 44: 163-188

Searle M P, Metcalfe R P, Rex A J, Norry M N. 1993. Field relations, petrogenesis and emplacement of the Bhagirathi leucogranite, Garhwal Himalaya. In: Treloar P J, Searle M P, eds. Himalayan Tectonics. Geol Soc Spec Publ Lond, 74: 429-444

Tindle A G, Breaks F W. 1998. Oxide minerals of the Separation Rapids rare-element granitic pegmatite group, northwestern Ontario. Can Mineral, 36: 609-635

Visona D, Zantedeschi C. 1994. Spodumene, petalite and cassiterite, new occurrence in Himalayan leucogranite pegmatites: Petrological implications. In: IMA. 16th General Meeting, Pisa. Abstract. 429

Wang R C, Che X D, Zhang W L , Zhang A C, Zhang H. 2009. Geochemical evolution and late re-equilibration of $\mathrm{Na}$-Cs-rich beryl from the Koktokay \#3 pegmatite (Altai, NW China). Eur J Mineral, 21: 795-809

Xie Y L, Wang B G, Li Y X, Li G M, Dong X L, Guo X, Wang L. 2015. Characteristics of pegmatite-related fluids and significance to ore-forming processes in the Zhaxikang $\mathrm{Pb}-\mathrm{Zn}$-Sb polymetallic deposit, Tibet, China. Acta Geol Sin-Engl Ed, 89: 811-821

Xie Y L, Li L M, Wang B G, Li G M, Liu H F, Li Y X, Dong S L, Zhou J J. 2017. Genesis of the Zhaxikang epithermal $\mathrm{Pb}-\mathrm{Zn}-\mathrm{Sb}$ deposit in southern Tibet, China: Evidence for a magmatic link. Ore Geol Rev, 80: 891-909

Yin L, Pollard P J, Hu S X, Taylor R G. 1995. Geologic and geochemical characteristics of the Yichun Ta-Nb-Li deposit, Jiangxi Province, South China. Econ Geol, 90: 577-585

Zeng L S, Gao L E, Xie K J, Jing J Z. 2011. Mid-Eocene high Sr/Y granites in the Northern Himalayan Gneiss Domes: Melting thickened lower continental crust. Earth Planet Sci Lett, 303: 251-266

Zhang J J, Santosh M, Wang X X, Guo L, Yang X Y, Zhang B. 2012. Tectonics of the northern Himalaya since the India-Asia collision. Gondwana Res, 21: 939-960 